\title{
Creating a climate and culture for sustainable organizational change
}

\author{
Mahsa Zolghadr ${ }^{\mathrm{a}}$ and Farid Asgari ${ }^{\mathrm{b} *}$
}

${ }^{a}$ M.A. in Marketing, Department of Marketing, Abhar Branch, Islamic Azad University, Abhar, Iran ${ }^{b}$ Department of Marketing, Abhar Branch, Islamic Azad University, Abhar, Iran

\section{H R O N I C L E}

Article history:

Received September 5, 2016

Received in revised format

October 2, 2016

Accepted October 4, 2016

Available online

October 5, 2016

Keywords:

Balance between Organizational

Behavior of Staffs

Managers' Decision Making

Effectiveness

Organizational Climate

Balance of Management

Commitment

Balance of Leadership

Balance of Communication

Balance of Learning

Balance of Motivation

\section{A B S T R A C T}

\begin{abstract}
The objective of this research is to investigate the balance between employees' organizational behavior and the method of managers' decision making in creating a good organizational climate in Gas Company of Zanjan province, Iran. The statistical population of this research includes 180 professions, staffs, and managers of the company and the study selects 120 people according to random sampling and by the use of Cochran formula. The descriptive-survey research method is cross sectional type. The questionnaire made by researcher was used for data gathering and its reliability and validity was approved. SPSS software was used for data analysis, correlation test was used for the effectiveness, and the effectiveness was specified. Also, LISREL software has been used for performing structural equations of model. The results of the research state that the variables of the balance between organizational behavior of staffs such as the balance of management commitment, balance of leadership, balance of communications, balance of learning, and balance of motivation were effective on its effectiveness in creating good organizational climate in the Gas Company of Zanjan province by managers' decision making methods.
\end{abstract}

\section{Introduction}

Human beings study in action step is called organizational behavior study. Organizational behavior is the systematic study of operations, actions, works, and attitudes of people who constitute the organization. In the organizational field, systematic study alternates intuitive judgment, namely the scientific evidence that is gathered under controlled conditions and is evaluated in a reasonable way and sought the effect in relation to any cause (Safarzadeh, 2007). Also, in relation to people performance, three factors possess essential role: production (productivity), absenteeism, and relocation of staff. Managers care about the quality and quantity of production of staff, while absenteeism and relocation of staff have an adverse effect on their yields and productions. Relocation of staffs causes increase of cost, and the organization always works with low expert peoples. Managers

* Corresponding author.

E-mail address: kapilmitta1007@gmail.com (F. Asgari) 
care employees' job satisfaction for three reasons: A direct relationship between job satisfaction and the productivity can be observed. Employees' job satisfaction of people maintains an adverse relationship with their absence and relocation. Managers feel human responsibility against employees. The objective of organizational behavior is to apply this knowledge for improving the performance of these organizations, or in other words, achieving organizational and social human objectives by performing better relationships. Meanwhile, the balance between managers' decision making and the organizational behavior is similar to pans of a balance scale. In a changing environment, traditional methods of managing is not desirable anymore. Peoples who want to lead the organizations of tomorrow should have new thoughts. Labor, customer expectations, and organizations are changing, so management must also change. The managers of $21^{\text {th }}$ century will be succeeded only by consciousness and alertness, being sensitive, hard work and interest in continuous learning.

As long as conflict is not destructive, people grow, and learn some lessons from it. The surveys of management methods in the past in this field show that managers mostly use of wrong strategy choices, that's mean managers mostly use of ineffective conflict solution strategies and based on pressure. In some cases, managers confirm that there is a problem, but do not perform a serious action, or state that the issue is under consideration, or more information is needed. One of the factors of the success of managers is the balance and movement of the organizational behavior. For instance, perceptual process is necessary for managers for various reasons. Perceptual process plays an important role in managers' decision making in the fields such as selection, appointment, and promotion of employees. For the reason of the importance of managers' decisions both for concerned peoples and organization, It is necessary to have a clear understanding of how genesis of these prejudices and their impacts on attitudes and behavior. Understanding the capabilities and staff traits is important because it contains people's characteristics and represents the capacity of the employee in comparison with motivation, which presents the employees' will for reaching the objectives of the organization. Clear understanding of differences of capabilities and traits of staff allows managers to do better job in the field of selection and appointment.

By a comprehensive and systematic attitude to the organization and management, we reach to the point that the effectiveness and success of the organization is realized when all resources and facilities of the organization including capital, raw materials, equipment and tools as well as human resources are combined, properly. Among all existing resources and facilities of the organization, human resources play specific and exclusive role. The specific importance of human resource in organization is that human is considered as the most important and most effective factor in order to achieve organizational goals; because human resource acts as designer and executive of organizational systems and processes, and human resource managers try to represent some programs for coordination between the goals of the organization and human resources purposes.

Due to recent developments in Gas Company of Zanjan Province, Iran, managers seek optimal decisions, and what is their first and foremost importance is behavior and the effectiveness of organization. Therefore, the objective of this research is to survey the balance between organizational behavior of staff by the method of managers' decision making and its effectiveness in performing a suitable organizational climate in the Gas Company of Zanjan province.

\section{Literature Review}

\subsection{Concepts and Theories}

Organizational behavior: organizational behavior is one of the interdisciplinary sciences that study the behavior of people, group, and organization. Organizational behavior study helps understand and improve the interactions between peoples and organizations (Jitwasinkul \& Hadikusumo, 2011). The purpose of organizational behavior studies is concentrated on identification and expression of events, 
regularly, description of the causes of these events, and finally controlling these situations such that the desirable behavior, being stable and the undesirable behavior does not repeat. Also, the aim of organizational behavior is to achieve the effectiveness of the organization (Robbins, 2001).

Managers' decision making: Generally, decision making is a mental process that all human beings deal with throughout their lives. Decision-making process is accomplished in the light of culture, perceptions, beliefs and values, attitudes, personality, knowledge and insight of the people, and these factors have mutual effect on each other. In contemporary management, decision-making is defined as a process of solving a problem, and often decision-making is called problem solving. It could be said that all of the activities and actions which are executed by human beings are the result of decision making process.

Organizational Climate: is a series of characteristics that describes an organization and distinguishes it from other organizations, it is almost stable during the time, and influences on the behavior of people in the organization. Organizational behavior could be stated in a simpler expression: "Organizational climate is the understanding of staff who are working in that organization” (Permarupan et al., 2013).

\subsection{Background Studies}

Khodayari (2014) surveyed the effect of organizational citizenship behavior (OCB) on the job performance. He believes that any tendency to citizenship behavior is importance because of increasing global competition. In his survey, organizational citizenship behavior variable had positive and significant effect on dimensions of job performance.

Sabahi and Dashti (2016) presented a study on the roles of emotional intelligence (EI) and job satisfaction (JS) on employees' organizational citizenship behavior (OCB). The study is performed among 140 randomly selected employees who worked for an Iranian bank in province of Karaj in 2014. The results of Pearson correlation stated that there were some positive and meaningful relationships between EI as well as JS with OCB. Moreover, the results of Stepwise regression implied that there were some positive and meaningful relationship between all components of EI, JS with OCB.

Shahbazi (2013) surveyed the effect of internal and external organizational factors (macroeconomic policies) on Entrepreneurial Behavior of middle managers in selected universities in Iran. The aim of this research was also to evaluate the effect of entrepreneurial climate of the organization and economic policies of government on the Entrepreneurial Behavior of middle managers in selected universities in Iran. Results of his research show that internal organizational factors (freedom and independence, access time and organizational boundaries) had significant and positive effect on the Entrepreneurial Behavior of middle managers in selected universities, and in contrast the internal organizational factor (reward and support), and monetary, financial, and foreign exchange policies had negative and significant effect on the Entrepreneurial Behavior of the so called managers. Among the surveyed variables, the effect of management support and trading policy were not significant on the Entrepreneurial Behavior of managers. Parsian and Mobaraki (2016) the role of entrepreneurial orientations was investigated on entrepreneurial identity of the municipality of Qom using a questionnaire consists of 18 items. The results indicated that entrepreneurial orientation influence significantly on entrepreneurial identity. MacKenzie et al. (1991) study investigates the effects of "organizational citizenship behaviors" and objective sales productivity on managers' evaluations of salespersons' performance. They reported that managers' subjective evaluations of salespersons' performance were determined as much by the salespersons' altruism and civic virtue as by objective productivity levels in the primary sample. Vuong et al. (2013) offered a new way of exploring the relationships between different dimensions of a business operation, namely the stages of business development, the methods of creativity and the major cultural values. 


\subsection{Conceptual Model of Research}

The conceptual model of research according to studies is plotted as follows:

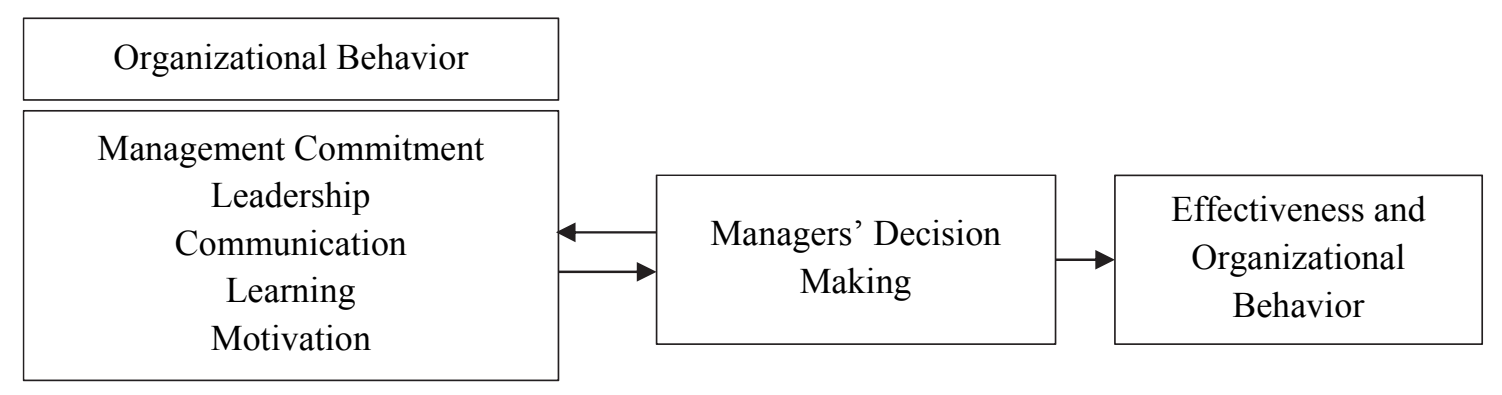

Fig. 1. Conceptual model of research

\subsection{Research Hypotheses}

- The balance of the management commitment and the method of managers' decision making is effective on its effectiveness on creation of desirable organizational climate in the Gas Company of Zanjan province.

- The balance of the leadership and the method of managers' decision making is effective on its effectiveness on creation of desirable organizational climate in the Gas Company of Zanjan province.

- The balance of the communication and the method of managers' decision making is effective on its effectiveness on creation of desirable organizational climate in the Gas Company of Zanjan province.

- The balance of the learning and the method of managers' decision making is effective on its effectiveness on creation of desirable organizational climate in the Gas Company of Zanjan province.

- The balance of the motivation and the method of managers' decision making is effective on its effectiveness on creation of desirable organizational climate in the Gas Company of Zanjan province.

\section{Research Method}

Descriptive research method is survey. Descriptive research describes and interprets what is available, and considers the existing conditions and relations, common ideas, current processes, clear effects, or trends in development. It cares primarily for now, even though mostly surveys also the events and effects of the past that is related to the existing conditions. Since in descriptive research, the characteristics of the society under study could be evaluated by survey, the present research is a descriptive research of the survey type. On the other hand, since the researcher has attended in a real life conditions of an organization, this research is really among field studies. Also, since this research is performed about a real, genuine, lively and dynamic subject, and its results could be used scientifically, is a practical research too. The objective of a practical research is development of practical knowledge in a special field.

\subsection{Statistical population, sampling method, and sample volume}

Statistical population of the research includes all 180 experts, staff, and managers of Gas Company in Zanjan province, Iran. Due to the inability of researchers to study all members of the society, we use sampling method using the Cochrane method as follows, 
$\mathrm{n}=\frac{\mathrm{Z}^{2}(1-\alpha / 2) \mathrm{pq} \mathrm{N}}{e^{2}(N-1)+\mathrm{Z}^{2}(1-\alpha / 2) \mathrm{pq}}$

Derived number estimated 120 people. For this purpose, 150 questionnaires were distributed to fully ensure that 120 questionnaires would be provided for analysis.

\subsection{Procedures and Tools for Collecting Information and Data}

Library procedure is used for collecting information and field procedure is used for collecting required data. Also, questionnaire tool is used for this purpose. The research's questionnaire has 28 items that distribution of items of each variable is specified in Table 1 as follows,

\section{Table 1}

Numbers and No. of items and amount of Cronbach's alpha of each variable in the questionnaire

\begin{tabular}{lcc}
\hline Item & Question No. & Cronbach's alpha \\
\hline Organizational Climate & $1-6$ & 0.82 \\
Organizational Behavior & $7-11$ & 0.88 \\
Managers' Decision Making & $12-18$ & 0.79 \\
Effectiveness & $19-28$ & 0.81 \\
\hline
\end{tabular}

\subsection{Reliability and Validity of Questionnaire}

Validity of questionnaire was measured with the use of experts and was approved. Also, reliability of questionnaire was evaluated by Cronbach's alpha, since the minimum required reliability coefficient for research's questionnaire is 0.7 , and according to Table 1 , computed alpha coefficient in the designed questionnaire is higher than 0.7 , so it could be concluded that applied questionnaire has required reliability.

\subsection{Methods and Tools for Data Analysis}

At first, the Kolmogorov-Smirnov test was used for evaluation of data normalization. Then, due to normalization of data distribution, Pearson correlation test was used for the evaluation of mutual relation between variables. Finally, method of structural equations modelling method was used for specifying one side relation of variables by using LISREL software.

\section{Research Findings}

\subsection{Evaluation of Data Normality}

Before the evaluation of hypotheses of research, the normality of variables of the study was investigated. For the evaluation of assumption of normality of variables of the study, one sample Kolmogorov-Smirnov test was used. The results of this test are given in Table 2. Due to establishing the normal assumption, parametric methods were used for the evaluation of hypotheses of research.

Table 2

The results of Kolmogorov-Smirnov test for the evaluation of normality

\begin{tabular}{lcccc}
\hline Variable & Sample & Statistic of test & Sig & Result \\
\hline Organizational Climate & 120 & 1.331 & 0.058 & Normal \\
Organizational Behavior & 120 & 1.316 & 0.063 & Normal \\
Managers' Decision Making & 120 & 1.284 & 0.074 & Normal \\
Effectiveness & 120 & 0.909 & 0.38 & Normal \\
\hline
\end{tabular}

\subsection{Evaluation of Hypotheses of Research}

Due to data normality, parametric methods were used for the evaluation of hypotheses and the results are represented in Table 3. 
Table 3

Research findings

\begin{tabular}{|c|c|c|c|c|c|c|}
\hline Hypothesis & $\begin{array}{c}\text { Independent } \\
\text { Variable }\end{array}$ & $\begin{array}{c}\text { Dependent } \\
\text { Variable }\end{array}$ & $\begin{array}{l}\text { Correlation } \\
\text { Coefficient }\end{array}$ & $\begin{array}{c}\text { Correlation } \\
\text { Type }\end{array}$ & $\begin{array}{c}\text { Significance } \\
\text { Level }\end{array}$ & $\begin{array}{l}\text { Result of } \\
\text { Hypothesis }\end{array}$ \\
\hline 1 & $\begin{array}{c}\text { Balance of } \\
\text { Management } \\
\text { Commitment }\end{array}$ & $\begin{array}{c}\text { Organizational } \\
\text { Climate }\end{array}$ & 0.784 & $\begin{array}{c}\text { Direct and } \\
\text { positive }\end{array}$ & $\begin{array}{c}\text { Less than } \\
0.001\end{array}$ & $\mathrm{H}_{0}$ is rejected \\
\hline 2 & $\begin{array}{l}\text { Balance of } \\
\text { Leadership }\end{array}$ & $\begin{array}{c}\text { Organizational } \\
\text { Climate }\end{array}$ & 0.943 & $\begin{array}{l}\text { Direct and } \\
\text { positive }\end{array}$ & $\begin{array}{c}\text { Less than } \\
0.001\end{array}$ & $\mathrm{H}_{0}$ is rejected \\
\hline 3 & $\begin{array}{c}\text { Balance of } \\
\text { Communication }\end{array}$ & $\begin{array}{l}\text { Organizational } \\
\text { Climate }\end{array}$ & 0.965 & $\begin{array}{l}\text { Direct and } \\
\text { positive }\end{array}$ & $\begin{array}{c}\text { Less than } \\
0.001\end{array}$ & $\mathrm{H}_{0}$ is rejected \\
\hline 4 & Balance of Learning & $\begin{array}{c}\text { Organizational } \\
\text { Climate }\end{array}$ & 0.876 & $\begin{array}{l}\text { Direct and } \\
\text { positive }\end{array}$ & $\begin{array}{c}\text { Less than } \\
0.001\end{array}$ & $\mathrm{H}_{0}$ is rejected \\
\hline 5 & $\begin{array}{l}\text { Balance of } \\
\text { Motivation }\end{array}$ & $\begin{array}{c}\text { Organizational } \\
\text { Climate }\end{array}$ & 0.96 & $\begin{array}{l}\text { Direct and } \\
\text { positive }\end{array}$ & $\begin{array}{c}\text { Less than } \\
0.001\end{array}$ & $\mathrm{H}_{0}$ is rejected \\
\hline
\end{tabular}

Due to the evaluation of hypotheses and derived results, it is specified that zero hypothesis is rejected in all of the hypotheses of research, and claims of the researchers about relationship among variables is notable.

\subsection{Structural Equations Modelling}

The relationship between two variables, regardless of their relationships to other variables was tested in un-correlation test. But, there is a possibility in structural equations that a series of mutual relationships between multi variables were tested simultaneously. In this research for evaluation and testing the suggested model of research, structural equations model has been used. After designing model by LISREL software, and receiving output, the following findings were resulted. Probability value (P-Value) of errors of model is 0.00 that shows that the errors of model is not significant at 0.05 level. The index of mean square root of remainders RMR is equal to 0.12 and it is small value, that this also states small error of model and its acceptable fitness.

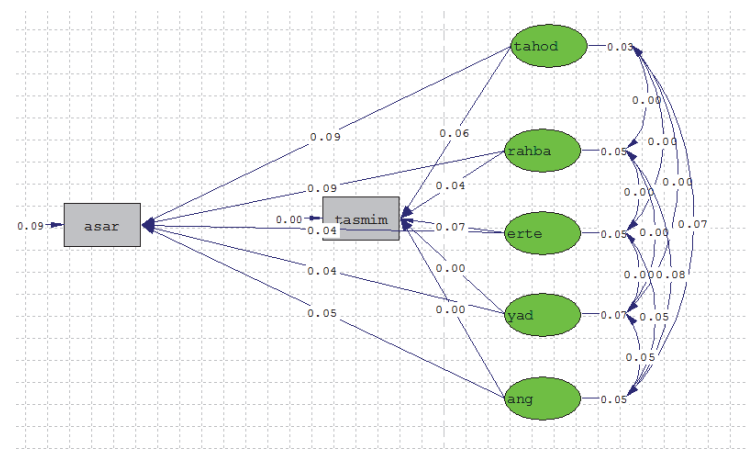

Fig. 2. The results of the implementation of LISREL program

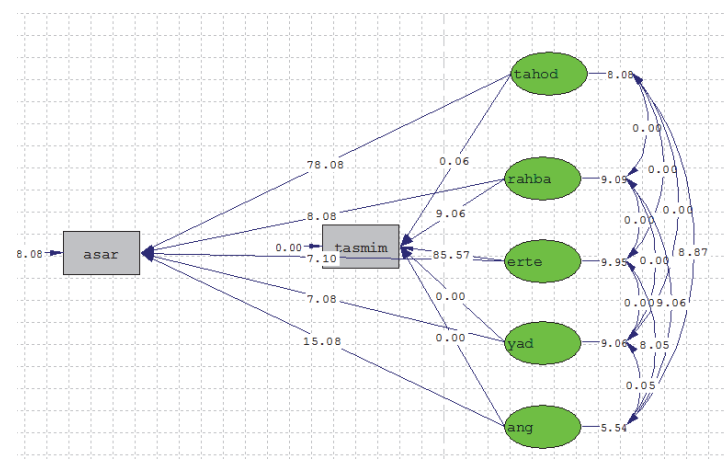

Fig. 3. Second order confirmatory factor analysis model after correction in significant case (tvalue)

One of the most valid indices which is applied for evaluation of fitness of model is goodness of fitness index (GFI) that is a measure of the relative value of variances and co-variances which is justified by model in a common way. This index can be considered as a characteristic similar to $\mathrm{R}^{2}$ in multi variable regression. When GFI is close to 1.0, model represents fitness with data. The GFI index in this model is equal to 0.93 , which shows that the fitness of model with data has reasonable fitness. The fitness index AGFI is modified value of GFI index for degrees of freedom. This characteristic is equivalent to applying mean square roots instead of total squares in the numerator and denominator (GFI-1). The 
above index in model is 0.908. RMSEA index or the Root Mean Square Error of Approximation for models to have a good fitness is less than $5 \%$. Any number higher than 0.8 represents reasonable error for approximation in the population. Since the value of this index is 0.051 it represents good fitness. Table 3 shows the fitness indices.

Table 3

Fitness model values

\begin{tabular}{cc}
\hline Index Type & Index Value \\
\hline P-Value & 0.00 \\
Chi-Square & 176.32 \\
RMR & 0.12 \\
GFI (Goodness of Fit Index) & 0.93 \\
Adjusted Goodness of Fit Index (AGFI) & 0.908 \\
RMSEA & 0.051 \\
NFI & 0.917 \\
CFI & 0.97 \\
\hline
\end{tabular}

Fig. 3 shows second order confirmatory factor analysis model after correction in significant case (tvalue). In fact, this model tests all measurement equations $\left(1^{\text {st }}\right.$ and $2^{\text {nd }}$ order $)$ by using $\mathrm{t}$ statistics. According to this model, path coefficient and/or factor loading in standard case is significant at 0.95 reliable level. If the value of the statistics is placed out of the range of -1.96 to +1.96 , and if the value of $t$ statistics is within this range, the factor loading is not significant with path coefficient. Path coefficient and/or factor loading at the reliable level of 0.99 is significant. If $t$ statistics is placed out of range of -2.58 to +2.58 , model in significance case shows that all of $1^{\text {st }}$ and $2^{\text {nd }}$ order factor loadings are significant at reliable level of 0.99 .

\section{Conclusions and Discussions}

Organizations that make qualified and fast decisions, and implement them in an effective form, contract more with their customers, more quickly enter the market, and defeat their competitors. The effectiveness of decision making includes four different dimensions. Of course, organizations which have very good performance, also make very good decisions. But, the point is that decisions making in these organizations mostly are executed faster than competitors, and also converting them to action are more effective, and they are executed by allocation of efforts and attention of people commensurate with those decisions. According to obtained results and under evaluation hypotheses, it is defined that all of organizational behavior dimensions had positive and significant relationships. Accordingly, under each of hypothesis, some suggestions are represented to officials and decision makers of Gas Company of Zanjan province:

\subsection{First hypothesis}

Development of management decision making must be aligned with the strategy of the company, and it should be implemented in order to support and strengthen the strategy. Issues such as globalization, decentralization, and fast track market, have obliged companies to evaluate the performance of their own. Today, the previous paradigms are no more effective, and understanding the need for change has become increasingly important. However, determining exactly how to convert these challenges into suitable opportunities is a factor that causes great concern to many senior executives. Organizations with high performance consider leadership development process as source and origin of competitive advantage. This process includes the following stages: 
1. Aligning leadership development with strategy development of the company:

The process of management decision making development as an effective part of changing process should be aligned with strategic objectives of the organization. Inventors of leadership development for understanding and helping to implementation of general strategy of company should not neglect any action. New leaders could eliminate challenges of business and limitations of global market only by alignment of their attempts.

\section{Focus on essential issues}

Development of management decision making would be focused more on the essential issues such as values, and necessary strategic issues all over the organization. While business units are focused more on their specific operations, the focus of leader development of the company has special attention to leadership, and mostly management skills, specially develops specific commercial skills. The leadership skills deal with main skills, namely the skills and behaviors that enable employees to perform their specified limit of duties, leadership development is established according to these main traits.

\section{Focus on development of human resource and job experience:}

In the transformational leadership development process, leading teams are those that emphasize the importance of human resources and job experience. Using transformational leadership in key positions of Human Resource Development does not mean disrespect to the exclusive aspects of discipline and hierarchy, but it means that the presence of transformational leaders guarantees reliability and partnership and usefulness of programs.

\section{Focus on Internal and External Factors:}

Management decision making development attempts should be executed by focusing on the internal environment, and awareness of the external environment. New business demands force the need for changing, but do not represent any criteria for how to create change (either starts by superior executive managers, or it is like as an absurd map). Implementation of a process for establishing skills, abilities, and leadership techniques that obliges the organizations to evaluate internal and external environments to answer is essential.

\subsection{Second Hypothesis}

Organizations must understand that the process of leadership development must be proportional to organizational culture for change creation. The first step for designing the process of leadership development is issuing this relationship by asking information of customers directly. Information from key customers has become a common process for organizations. In order to analysis needs properly, organizations emphasize on a number of tools including the following items:

Using executive managers in main positions of human resource development,

Official communications with attempts of strategic programs,

Vast dialogues and debates with business and commerce' leaders.

Internal and external evaluations of customers

These official evaluations of needs may seem like as a clear action in performing the process of leadership development. These evaluations do not performed in any way at the macro level. The role 
of leaders in the all levels is clarifying people that they are worthy for accessing more than they think, and they should not be satisfied with their positions. Management decision in the third millennium must be occurred by some interactions between great leaders of company (senior managers) and members of the organization (People inside the organization).

\subsection{Third hypothesis}

General and common policy of organizations is on the basis that the consequence of evaluation sessions focus on performance of staff and not on the rate of salary and benefits. Understanding this policy is not always possible for staff. Therefore, evaluator always must care that in the session of performance evaluation prohibit of entering to the areas of salary and benefits, and keep focus of the session only on the evaluation of performance of staff. Of course it is normal to have someone ask for an increase in employee's salary after having been praised by the evaluator; but if the evaluator does not have the authority to do so, or the policy of salary increase has another basis, not only the performance evaluation will have reverse consequences, but it will also cause the employees to question the evaluator and eventually the organization's policies (Henri, 2004; Lu et al., 2015). On the other hand, evaluating jobs is a way to examine the value of a specific job or organizational position, and not the operator's performance. Therefore, the amount of salary and benefits considered for a job or organizational position is determined based on the job's value, and it does not depend on the operator; thus the matter must be considered by the evaluator.

To increase the sense of participation between the managers and employees, it is suggested that the managers keep the employee informed about important plans and issues. This will cause all the members of the organizations to make more effort in helping the managers to reach the organization's goals.

\subsection{Fourth Hypothesis}

The results gained from analyzing the data and hypotheses show that motivational factors had a positive and significant relationship with the performance of the employees. In other words, motivational factors influence the employees' performance. The results also show that the five variables of commitment and service motivation, training satisfaction, salary and benefits satisfaction, job independence and organizational support influenced the performance of the organization's employees.

It is suggested that the management emphasizes these strategies in order to benefit from their roles in improving organizational performance. Of course, in this regard, the decisions of the Human Resource management should be based on strategies, and they should turn these strategies into a set of coordinated actions.

\section{References}

Lu, C. M., Chen, S. J., Huang, P. C., \& Chien, J. C. (2015). Effect of diversity on human resource management and organizational performance.Journal of Business Research, 68(4), 857-861.

Henri, J. F. (2004). Performance measurement and organizational effectiveness: Bridging the gap. Managerial Finance, 30(6), 93-123.

Jitwasinkul, B., \& Hadikusumo, B. H. (2011). Identification of important organisational factors influencing safety work behaviours in construction projects. Journal of Civil Engineering and Management, 17(4), 520-528.

Khodayari, N. (2014). The effect of spiritual intelligence on organizational citizenship behavior and job performance: A case study of Tehran Municipality, Master's thesis, PNU (Ministry of Science, 
Research, and Technology) - light Message Center Tehran - Faculty of Management and Accounting.

MacKenzie, S. B., Podsakoff, P. M., \& Fetter, R. (1991). Organizational citizenship behavior and objective productivity as determinants of managerial evaluations of salespersons' performance. Organizational behavior and human decision processes, 50(1), 123-150.

Parsian, M., \& Mobaraki, M. (2016). Investigating of the effect of entrepreneurial orientations on formation of entrepreneurial identity.Management Science Letters, 6(10), 627-634.

Permarupan, P. Y., Saufi, R. A., Kasim, R. S. R., \& Balakrishnan, B. K. (2013). The Impact of Organizational Climate on Employee's Work Passion and Organizational Commitment. ProcediaSocial and Behavioral Sciences, 107, 88-95.

Pourtabatabaei, M.R. (2013), A Conceptual Model of Human Resource Strategic Management, Emphasizing the Employees' Culture, Training and Abilities; Essays from Conferences in Iran. The Second International Conference of Industrial and System Engineering. Islamic Azad University, Najaf Abad.

Robbins, S. P. (2001). Organizational behavior, 14/E. Pearson Education India.

Sabahi, A., \& Dashti, N. (2016). The effect of emotional intelligence and job satisfaction on organizational citizenship behavior. Management Science Letters, 6(7), 475-480.

Safarzadeh, H. (2007). Design and explain model of organizational communications in the process of organizational entrepreneurship (with emphasis on distribution companies throughout the country). The Journal of Behavior, 12(14), 132-119.

Shahbazi, Sh. (2013). Effect of Internal and external organizational factors (macroeconomic policies) on Entrepreneurial Behavior of middle managers of selected universities in Iran. Institute for Humanity sciences and Cultural Studies, Institute of Economic Affairs.

Vuong, Q. H., Napier, N. K., \& Tran, T. D. (2013). A categorical data analysis on relationships between culture, creativity and business stage: The case of Vietnam. International Journal of Transitions and Innovation Systems, 3(1), 4-24.

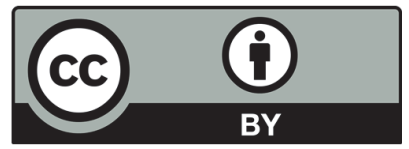

(C) 2016 by the authors; licensee Growing Science, Canada. This is an open access article distributed under the terms and conditions of the Creative Commons Attribution (CC-BY) license (http://creativecommons.org/licenses/by/4.0/). 